\title{
15
}

\section{Implementation of a Program to Prevent Sanitary Sewer Overflows by Reduction of Stormwater Inflow}

\author{
Steven J. Wright and Mark TenBroek
}

The City of Ann Arbor, Michigan suffered from recurring episodes of basement flooding from sanitary sewer backups during major rainfall events. An investigation was conducted to identify the circumstances controlling the flooding and to evaluate alternatives for mitigation of the flooding. Five major areas subjected to flooding were identified and a monitoring program was conducted in these areas. Due to the distributed nature of the flooding occurrences, a number of system deficiencies were identified. In addition, it was observed that system flows increased rapidly after the commencement of rainfall, leading to the conclusion that contributions from footing drains in older residences were a major contribution to the increased system inflows. Options investigated for mitigation of the basement flooding included system capacity increase by construction of relief sewers and pipe bursting, provision of underground storage facilities, and implementation of a footing drain disconnect program. Disconnection of footing drains was indicated to be the least cost alternative in most of the areas although uncertainties existed in the exact contribution of footing drains to system inflows due to the limited number of homes investigated during the field study. Additional considerations such as periodic overflows at the wastewater treatment plant during high rainfall events and pending sanitary sewer overflow regulations led to the decision to implement the footing drain disconnect program city-wide.

Wright, S.J. and M.J. TenBroek. 2003. "Implementation of a Program to Prevent Sanitary Sewer Overflows by Reduction of Stormwater Inflow." Journal of Water Management Modeling R215-15. doi: 10.14796/JWMM.R215-15.

(C) CHI 2003 www.chijournal.org ISSN: 2292-6062 (Formerly in Practical Modeling of Urban Water Systems. ISBN: 0-9683681-7-4) 


\subsection{Introduction}

Basement flooding due to sanitary sewer overflows (SSOs) is often caused by infiltration/inflow during rainfall events. There are several potential sources of the infiltration/inflow including defects in manholes and piping (Dillard et al., 1993 and Wade, 2000), illegal connections between storm and sanitary sewer systems (Rowlett, 1992), and the formerly common practice of connecting footing drain lines to the sanitary sewer system (Paulson et al., 1984). In order to mitigate the effects of increased flows in the sanitary sewer system, a number of potential alternatives may be pursued. Choices involve increasing system flow capacity by pipe replacement or rehabilitation (Mines, 1996 and Dillard et al., 1993), provision of retention storage (Rowlett, 1992), or removal of infiltration/inflow sources (Kurz, 1997 and Duggan et al., 1998). The selection of the appropriate solution for a given system depends on the specifics of the particular system and therefore relies on an adequate investigation of the sewer system response to rainfall events. This chapter describes a study performed for the City of Ann Arbor, Michigan including the basis for the selection of an alternative to mitigate the SSO problems.

The City implemented a program to eliminate SSOs that had caused periodic basement flooding following periods of intense rainfall. The impetus for the program was citizen complaints following an extreme rainfall event in August of 1998. The program was initiated with the formation of a task force composed of citizens affected by the flooding, city utilities personnel and additional representatives representing expertise related to water resources issues. An early effort of the task force was to select a consultant to perform a study of the sanitary sewer system, to analyze the results of the study and to perform an alternatives analysis in order to provide recommendations to the Ann Arbor City Council for mitigation of the basement flooding problem. The results of the study and the program being implemented are described below.

\subsection{Background}

The City of Ann Arbor, Michigan operates a separated sanitary sewer system for a population of approximately 200,000 . The city has records dating back to about 1960 related to basement flooding incidents associated with sanitary sewer backups, primarily during high intensity rainfall events. Since the late 1970 's it has been illegal for newly constructed homes to use sumps pumps to discharge flows from footing drains into the sanitary system. However, there 
are an estimated 20,000 homes throughout the city that predate the ordinance with footing drains discharging to the sanitary sewer system, potentially contributing significant inflows into the system during precipitation events.

A major rainfall event occurred on August 6, 1998 with the precipitation indicated in Figure 15.1 recorded at a rain gauge located on the south side of Ann Arbor. Over 150 complaints of basement flooding were made following this rainfall. Five areas of concentrated flooding were identified on the basis of these complaints, three on the southwest side of the city and two on the northeast side. These study areas had flow contributions from areas that range from about 30 to 290 ha. Although these areas make up only a combined 5\% of the city's land area, over $50 \%$ of the recorded flooding complaints have originated from these areas.

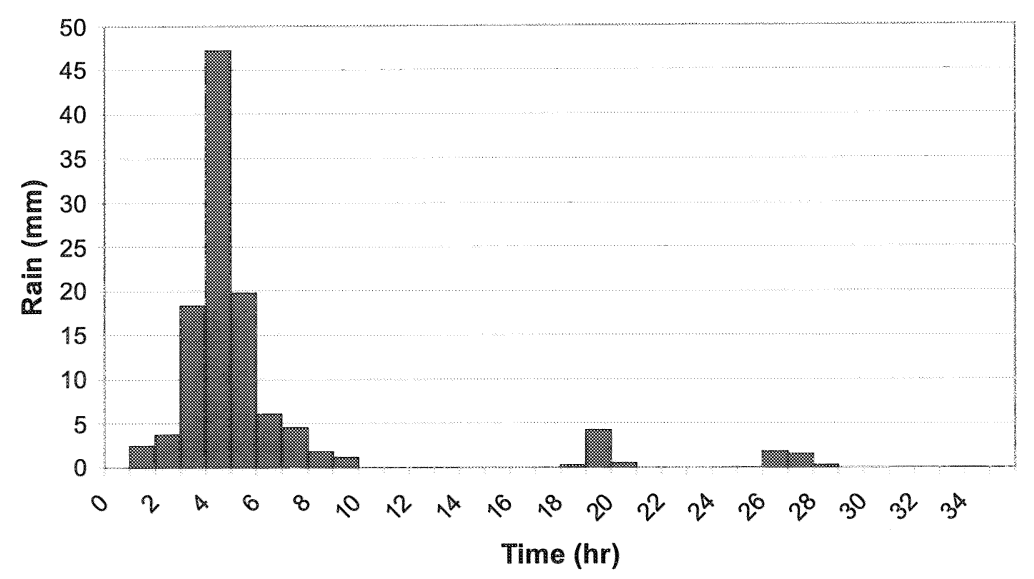

Figure 15.1 Rainfall distribution during August 6, 1998 storm.

In response to the 1998 flooding, the City Council appointed a task force in the summer of 1999 with the mission of initiating an engineering study to identify the source of the sewer backup problems and to recommend a plan for eliminating or reducing the impact of future sewer backup events. The task force was composed of City staff members from the Department of Public Services, Water Utilities and Administration, homeowners affected by the flooding, and outside technical professionals. The five areas were selected for an in-depth study to identify the system deficiencies leading to the flooding and to determine potential solutions to alleviate the basement backups. The engineering firm of Camp, Dresser \& McKee (CDM) was selected to perform an engineering study with the following components: 
- Flow monitoring was implemented in each of the affected areas. Sewer stages and flow rates were monitored at key location within the system.

- In addition to the flow monitoring, activities were performed to verify the location, configuration and characteristics of the collection system sewers and manholes. Manhole inspections, downspout inspections, dye testing and smoke testing were also performed to identify potential sources of inflow into the sanitary sewer system

- Numerical models were developed in order to simulate discrete rainfall events measured during the flow monitoring study. Detailed models were developed for each of the study areas as well as a trunk sewer model for the complete system. Specifically, the ability of the models to describe the magnitude and extent of basement flooding observed during a major rainfall event that occurred during the monitoring program was used as a basis for model verification. The model was then used to define the system deficiencies leading to the flooding.

- Potential mitigation solutions were identified and were evaluated with the numerical models to determine their effectiveness in elimination of the basement flooding problems. Estimated costs were also developed for implementation of these alternatives.

- A major effort was made to communicate the results of these studies to the general public in order to keep them informed of the progress of the investigation and to assess their acceptance of the potential solutions.

- The task force was charged with making a recommendation to the City Council as to the most effective approach to alleviating the SSO problems.

CDM met regularly with the task force to review progress on the monitoring program, to define potential mitigation alternatives, and to redefine the scope of the project work as necessary.

\subsection{Study Areas}

The five study areas were defined on the basis of sewer connections. All except for the Glen Leven study area had a single discharge point. The Orchard Hills study area had a retention basin constructed under the street in 1979 to attempt 
to alleviate basement flooding problems that had occurred prior to that date. The Dartmoor study area received substantial flow from an upstream pumping station. Up to two pumps could be used to pump sewage from a retention storage facility into the sewer passing through the Dartmoor area. On the order of 100 homes in these five study areas, primarily in low lying areas, suffered from basement flooding during the August, 1998 storm.

\subsection{System Investigation}

The system investigation that was performed is described in this section. The investigation involved an inspection program, a monitoring program, and the development of numerical models.

\subsubsection{Inspection Program}

A comprehensive inspection program was conducted in each of the five study areas. The downspouts at every home were inspected to determine possible discharges to the sanitary sewer system; only two homes had these illegal connections. Although a significant percentage of homes were found to have downspouts that extended less than 1.5 meters from the building perimeter, it was also noted that space limitations often precluded longer extensions. Each accessible manhole was inspected to determine the manhole conditions as well as the sewer connections into the manholes. In general, the manholes were determined to be in good condition with only 24 minor maintenance items identified. Smoke testing was performed in the Bromley and Orchard Hills study areas in 1998 to determine potential sources of infiltration and inflow. Few problems were identified in this study and given the good conditions of the inspected manholes, it was judged to be unproductive to perform additional smoke testing in the current study. The general conclusion was that the sewer system was in generally good condition with little infiltration/inflow through manholes and pipe defects.

\subsubsection{Monitoring Program}

The monitoring program was begun in May, 2000 and was preceded by the installation of rain gauges, flow meters and water level sensors in each of the five study areas. Rain gauges were installed near the center of each study area. Seven discharge and level sensing stations were installed on key trunk sewers 
Table 15.1 Rainfall volumes.

\begin{tabular}{|c|c|c|c|}
\hline \multirow[t]{2}{*}{ Study Area } & \multicolumn{3}{|c|}{ Number of storms that exceeded } \\
\hline & $1 "$ & $2 "$ & $3 "$ \\
\hline Orchard Hills & 12 & 2 & 0 \\
\hline Bromley & 12 & 3 & 1 \\
\hline Dartmoor & 11 & 2 & 1 \\
\hline Glen Leven & 11 & 3 & 1 \\
\hline Morehead & 11 & 2 & 1 \\
\hline
\end{tabular}

near the outlets of each of the five study areas. In addition, 21 peak level recorders were installed at various upstream locations in each study area. This installation preceded a period of considerably above average rainfall. Table 15.1 summarizes some gross statistics regarding rainfall events for which flow records were obtained during the monitoring period between May and November. In particular, a major rainfall event occurred on the evening of June 24 with total rainfall between 2.9 and 4.0 inches $(63.5-102 \mathrm{~mm})$, depending on the study area, recorded over about a six hour period. Figure 15.2 indicates the precipitation distribution recorded in one of the study areas. For a storm of its duration (4-6h) the larger rainfall volume represents about a $200 \mathrm{y}$ return period event. This event resulted in substantial basement flooding in many of the same homes as the August 1998 event mentioned above. Many of the rainfall events resulted in surcharged conditions within the sanitary sewer system, although conditions were not severe enough to result in basement flooding.

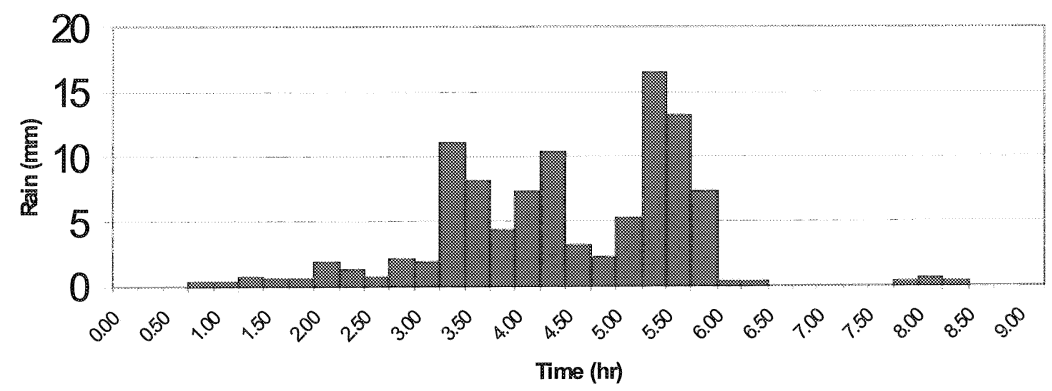

Figure 15.2 Rainfall distribution measured in Glen Leven study area on June 24-25, 2000.

The continuous discharge records were used to determine dry weather flow statistics. The ratios of the maximum recorded discharge (during the June 24-25 event) to the average dry weather flow were in the range of 10-30 depending on the study area with most above 20 . 
In addition to the basic flow monitoring, attempts were made to determine inflows into the sewer system from individual house leads. The system was inspected to determine locations where house leads connected into the sewer system at manholes where there would be direct access to the outlet. Sixteen such installations were identified and a temporary extension was fixed to the outlet so that flow could be collected in a bucket. The bucket and a stopwatch were used to estimate the flow rate. Two rainfall events were monitored by field crews. Two to three measurements were made at each location during each rainfall event. Figure 15.3 presents the results of the measurements at one such outlet. One notable result is the rapid response of the outflow to the commencement of the rainfall. Since the roof downspouts were disconnected from the sanitary sewer, it was deduced that this rapid inflow was primarily due to inputs from the footing drains surrounding the home. Although not observed at all locations, this rapid response to rainfall was a common observation, implying that there are direct flow paths from the ground surface to the footing drains at many homes.

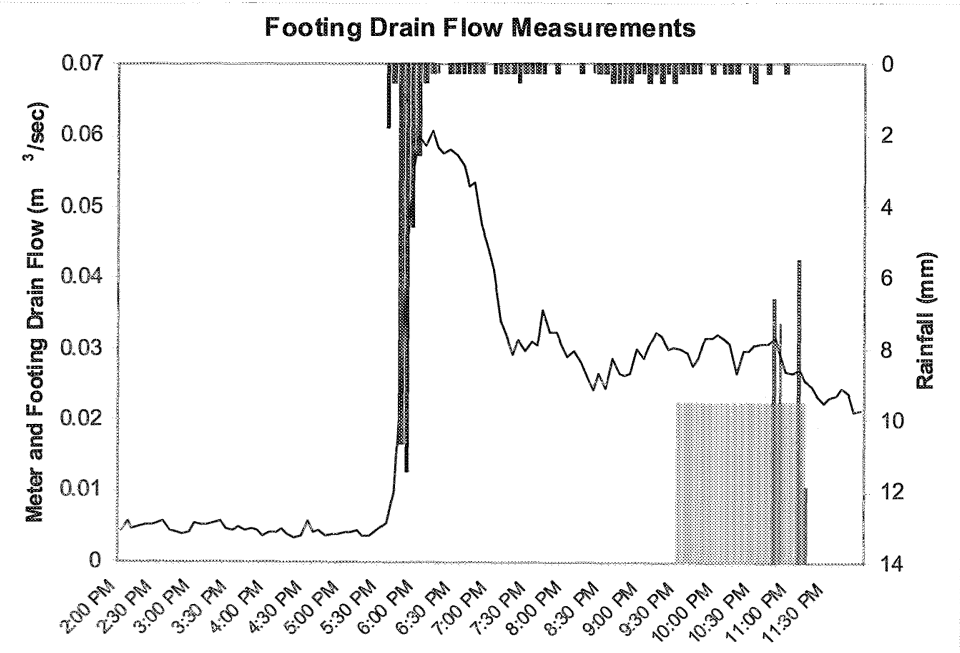

Figure 15.3 Sanitary sewer flow meter response to precipitation.

Footing drain inflows were monitored during two rainfall events, on August 17, 2000 and on September 11, 2000. The August 17 storm was short and produced a limited response. The September 11 storm produced between 1.57 to 1.8 in $(40-46 \mathrm{~mm})$ of rainfall over about a five $\mathrm{h}$ period. Footing drain 
flow measurements were made over a period of fairly steady rainfall. The measured flows ranged from 0 to $11.5 \mathrm{~L} / \mathrm{mim}$ with an average of $5.4 \mathrm{~L} / \mathrm{m}$ for all locations monitored. Footing drain flows separated by study area are presented in Table 15.2. Although there is some variability, the four study areas monitored yielded fairly consistent average flows.

Table 15.2 Average footing drain flows.

\begin{tabular}{lcc}
\hline Study Area & \#Leads Monitored & $\begin{array}{c}\text { Average Flow } \\
\text { (liters/minute) }\end{array}$ \\
\hline Orchard Hills & 5 & 4.2 \\
Bromley & 4 & 7.3 \\
Dartmoor & not monitored & \\
Glen Leven & 5 & 6.9 \\
Morehead & 2 & 5.4 \\
\hline
\end{tabular}

The rainfall, sanitary sewer flow and estimated footing drain flows were compared for each study area. This information is presented for the Bromley study area for the September 11 storm in Figure 15.3. The rainfall is plotted at the top of the figure. The flow meter data shows a response that is similar in shape to the rainfall pattern, peaking about fifteen minutes after the rainfall peak after which it leveled off for a few hours before dropping back to a dry weather flow pattern. An estimate of the contributions of all footings drains in the study area was made by assigning the average footing drain flow of $5.4 \mathrm{~L} / \mathrm{min}$ to all homes with footing drains in the study area. This is indicated in Figure 15.3 as the lighter colored vertical lines during the time period that house lead monitoring was conducted anywhere in the system. The flows monitored in this study area but assigned to all homes with footing drains in the study area are indicated by the darker vertical lines. This exercise indicates that as much as $90 \%$ of the wet weather flow from this study area could have been created by footing drain flows. Similar results were found for three of the other four study areas. The Dartmoor study area indicated a somewhat lower but still significant percentage of the wet weather flow to be contributed by footing drains. This estimate is based only on the average flow from all monitored leads since no measurements were made in this study area. Although the number of individual leads monitored was a small percentage of the total and the footing drains flows were somewhat variable, it is clear from these results that significant reduction of peak flows in the sanitary sewer system could be achieved by a footing drain disconnect program and this control strategy was included as one of the alternatives to mitigate the basement flooding problems. 


\subsubsection{Numerical Model Development}

SWMM was implemented to simulate the behavior of the sanitary system in order to compute the system response to various control alternatives. The modeling was performed at two levels: a trunk sewer model and local models in each of the five affected areas. The trunk sewer model consisted of the sewer mains in the entire system and was used for two primary purposes. The first was to define current system bottlenecks downstream of the study area that may be creating backwater conditions contributing to flooding in the affected areas. The second was to determine the system response to mitigation alternatives that provided local relief by increasing flow capacity. The intent was to determine if local relief alternatives would displace flooding further downstream. The local models were used to evaluate the impacts of all identified alternatives that are discussed in more detail below.

Rainfall and flow data were analyzed for the entire system as well as for the individual study areas to determine rainfall dependent infiltration and inflow. Estimates were made of the total volume carried by the sanitary sewer system (in excess of dry weather flows) and these were divided by the estimated rainfall volume minus initial abstractions. A greater response was observed during dormant seasons compared to months with active evapotranspiration. The percentage of rainfall dependent infiltration/inflow of rainfall (above initial abstractions) for the entire system averaged 3.8\% for dormant season rainfall and $2.0 \%$ during the growing season. These percentages are typical for sanitary sewer systems in good condition.

The trunk sewer model was based on a similar previous modeling effort that was used to determine limitations to system capacity. The model was updated to reflect changes in system operation that had occurred in the intervening years in addition to corrections required to reflect an improved current understanding of the connections in the sewer system. The trunk sewer model was calibrated using the August, 1998 and the June, 2000 storm events described above. The calibration was performed using hourly flow data available from the Ann Arbor wastewater treatment plant for these two events. This data was equalized flow at the plant and estimates had to be generated of the flows leaving the collection system. Rainfall gauges in the five study areas as well as several other recording stations were used to estimate the precipitation patterns for the June, 2000 event; more limited data was available for the August, 1998 event. The rainfall dependent infiltration/inflow relationships were used to estimate stormwater contributions to the sanitary system flows. Figure 15.4 indicates the calibrated flows for the June, 2000 event. The 


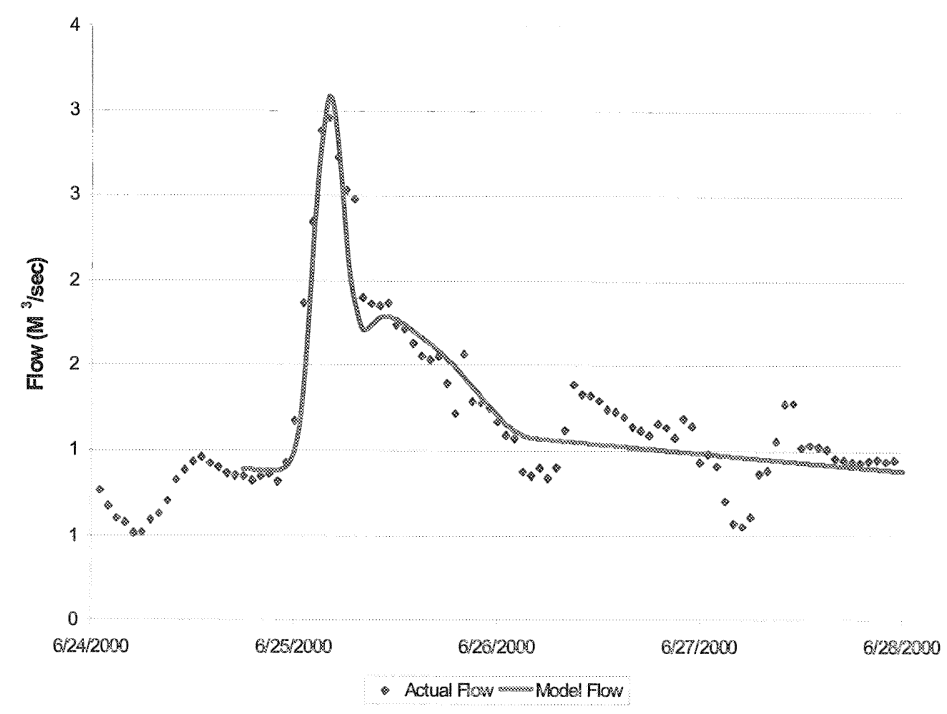

Figure 15.4 Trunk model calibration for June 24, 2000 event.

calibrated model was used to identify capacity problems in the current collection system using Design Condition I defined below. Although capacity problems were noted in some specific areas, the overall system was determined to be generally adequate for conveying flows associated with a major rainfall event.

Individual models at a higher level of detail were prepared for each of the study areas in order to adequately investigate potential resolutions to basement flooding problems in the study areas. The Bromley and Orchard Hills study areas share a common outlet so were included in a single model. The models were calibrated to Rainfall Response Factor and Initial Abstraction parameters for several rainfall events. Basement floor elevations had been estimated for the homes that had been subject to flooding as well as the approximate depths of flooding. The study models were checked for their ability to reproduce system hydraulic grade lines consistent with these flooding levels, in particular for the June, 2000 storm. These models were then used to evaluate alternatives to eliminate the basement flooding problems.

To evaluate the level of system modifications required to mitigate the basement flooding problems, design conditions were defined and implemented in the numerical model. In the case of alternatives that resulted in increased flows in the trunk sewer system, improvements to prevent surcharging of the 
trunk sewers were also determined. Three different design conditions were developed and used in the numerical model. In terms of increasing severity, these conditions were:

- Design Condition I was based on the June, 2000 rainfall event. Basically, it consisted of the highest recorded rainfall measured in any of the five study areas (4.15 inches, $105 \mathrm{~mm}$ ) as well as the observed time distribution of rainfall. The rainfall dependent infiltration/inflow was, however, based on the dormant season response.

- Design Condition II was based on a higher total rainfall volume (4.5 inches, $114 \mathrm{~mm}$ ) with the growing season rainfall dependent infiltration/inflow. The rainfall distributions for the June, 2000 and the August, 1998 events were scaled to this total volume of rainfall and the worst case of these two conditions were used for evaluation of system adequacy.

- For Design Condition III, a similar approach to design condition 2 was employed, except that a lower rainfall volume ( 4.0 inches, $102 \mathrm{~mm}$ ) was used with the dormant season rainfall dependent infiltration/inflow.

System evaluation was performed by evaluating the current system with Design Condition I and determining required system upgrades that would prevent system surcharging. Once potential system modifications were identified, the revised systems were simulated for Design Conditions II and III to ensure that hydraulic grade lines remained below basement floor elevations. Although the design conditions represent extreme hydrologic events, estimated in excess of a $200 \mathrm{y}$ return period, the inclusion of such extreme conditions was felt to be necessary in order to retain credibility with the public, given the occurrence of two major events in less than a two year period of time.

\subsection{Alternative Evaluation}

Four mitigation alternatives were investigated. Basically, these consisted of:

- Providing relief sewers both within the affected areas and in any downstream trunk lines sufficient to eliminate surcharging in the system during the design event

- Using pipe bursting technology (e.g Yach, 1997 and Jennings, 1995) to increase the capacity of existing sewers. Since there is a practical limit to the increase in pipe diameter that can be 
achieved through conventional pipe bursting technology, this control option was used in combination with relief sewers wherever the required increase in capacity could not be achieved by pipe bursting.

- Providing retention storage within the affected areas. Again, the use of retention storage was accompanied by installation of relief sewers or pipe bursting in order to meet the mitigation objectives.

- Implementation of a footing drain disconnect (FDD) program. Initially, this control strategy was designed to be implemented only in the areas identified as connected to the local systems impacted by flooding. Providing FDD at the homes previously impacted by the sanitary sewer overflows was not a viable control alternative since this would not remove sufficient inflow into the system to prevent surcharging during major rainfall events. Also, preventing sewer backups into the previously flooded basements would only shift the flooding problem to adjacent properties.

Since there would be a time period required for implementation of any of the above alternatives, an immediate plan to eliminate flooding in the previously impacted homes, as well as adjacent ones deemed susceptible to flooding, was instituted. This plan involved a disconnection of the footing drains from those homes and the installation of check valves at the exit of the sanitary sewer lead from the home to prevent backflows into the basement during surcharge events. A pilot program was conducted to gain experience in implementation aspects and costs to more clearly identify issues associated with potential implementation of a FDD program. Installations were made in eleven homes that had experienced previous basement flooding. The installation consisted of the installation of check valves for backflow prevention, re-routing footing drain flows to a new sump and installation of sump pumps to discharge these flows out of the homes. A water-powered backup pump was installed to protect against failure of the primary pump due to loss of electrical service. Feedback from both the homeowners and the plumbing contractor that performed the installations was used to identify modifications to the procedure in the event the FDD option was identified as the preferred alternative.

The study area models were used to determine the impact of proposed mitigation alternatives in the study areas and to determine the level of required changes. As mentioned previously, a level of service associated with prevention of surcharge conditions in the sanitary sewer system was used to define adequacy of a mitigation alternative. The options involving relief alternatives 
would result in increased flows downstream in the system. The trunk sewer model was used to evaluate required changes to the remainder of the system in order that these increased flows would not create capacity problems elsewhere in the system or produce a backwater condition in a study area such that the basement flooding problems could not be resolved locally.

Estimated costs were developed for each of the mitigation alternatives for each of the study areas. Present worth costs for two of the study areas are presented in Table 15.3 as representative of all five study areas (for more details on the cost estimates, see Sanitary Sewer Overflow Prevention Advisory Task Force, 2001). Lifecycle costs associated with increased maintenance, etc. were included for the various alternatives based on an assumed interest rate of $8 \%$ and a project life of $30 \mathrm{y}$. In the case of the FDD alternatives, the life cycle costs are negative due to the reduction of flows to be treated at the wastewater treatment plant. Costs for the FDD program included the actual disconnection as described above for the pilot study in addition to providing installation of a shallow buried drain line near the street to convey the sump pump discharges to the nearest storm drain. A range of costs was assigned to the FDD alternatives due to uncertainty in the number of homes required to be disconnected in order to achieve the desired level of service.

Table 15.3 Estimated project costs for various mitigation alternatives (cost in US millions).

\begin{tabular}{lllll}
\hline \multicolumn{1}{c}{ Alternative } & Construction & $\begin{array}{c}\text { Downstream } \\
\text { Improvements }\end{array}$ & $\begin{array}{c}\text { Life } \\
\text { Cycle }\end{array}$ & Total \\
\hline Orchard Hills Study Area & & & & \\
\hline Relief Sewers & 2.86 & 0.42 & 0.05 & 3.33 \\
Upsizing & 2.79 & 0.42 & 0.03 & 3.24 \\
Storage & 2.24 & 0 & 0 & 2.24 \\
Footing Drain Disconnect & $1.93-2.32$ & 0 & -0.26 & $1.67-$ \\
& & & & 2.06 \\
\hline$\quad$ Dartmoor Study Area & & & & \\
\hline Relief Sewers & 1.79 & 3.95 & 0.12 & 5.86 \\
Upsizing & 1.81 & 3.95 & 0.10 & 5.86 \\
Storage & 2.66 & 0 & 0.01 & 2.67 \\
Footing Drain Disconnect & $1.50-1.92$ & 0 & -0.41 & $1.09-$ \\
& & & & \\
\hline
\end{tabular}

Estimates of the minimum number of homes required to have footing drain disconnects was based on the assumption that $90 \%$ of the infiltration/inflow was due to footing drain inputs, a percentage indicated by the monitoring results. A more conservative approach assumes that only $70 \%$ of the 
infiltration/inflow was from footing drains and required a larger percentage of homes with footing drains to be disconnected from the sanitary sewer system. It was assumed that all footing drains in the areas historically subject to flooding would be disconnected and that additional homes in the study area with connected footing drains would be disconnected. The percentage of additional homes required to have footing drain disconnections ranged from a low of 55$70 \%$ in the Glen Leven study area to a high of $80-100 \%$ in the Dartmoor area. A series of public meetings wws conducted to explain the nature of the problems, the proposed SSO relief alternatives, as well as the estimated costs to gauge public response to the proposed alternatives.

The FDD alternative was indicated to be one of the lowest cost alternatives in each of the affected areas based on construction costs and even more so when the life cycle cost benefits attributed to lower flows to be treated at the wastewater treatment plant were considered. However, this alternative had more uncertainty associated with it simply because the amount of inflow reduction achievable from FDD could only be estimated from the relatively few homes metered during the monitoring program. In spite of this uncertainty, this alternative was appealing to the task force charged with evaluating the alternatives and making a recommendation to the Ann Arbor City Council.

A major implementation issue was the indication that a large percentage of homes (ranging from an estimated low of $50 \%$ in one study area to all of the homes in some study areas) with connected footing drains that had never been subjected to basement flooding would be required to undergo the inconvenience of the disconnection procedure. It was clear that a voluntary program would never achieve that level of compliance, even one in which the disconnection costs would be born by the city. This led to discussions with the city attorney on implementation issues of a mandatory program of footing drain disconnections, thereby requiring $100 \%$ participation in all study areas and somewhat increasing the costs of the FDD program. The major issue that arose was the selective enforcement of such a mandatory program in limited areas of the city. This concern along with indications that impending legislation would more severely restrict sanitary sewer overflows during wet weather conditions led to the consideration of a city-wide program of footing drain disconnects. A major advantage of this approach is that it would significantly postpone upgrades to the wastewater treatment plant capacity and the sewer collection infrastructure due to the reduction of wet weather flows which control the system capacity. However, it also came at the expense of a significant increase in the program costs. An initial estimate of 2650 disconnects in the five study areas plus an additional 315 in homes subject to localized flooding problems 
elsewhere in the city was expanded to an estimated total of 20,000 disconnects. Similarly, the construction costs estimated at 18.6 US million dollars were increased to the 80-100 million US dollar level. This large a program would be spread over a 15-20 y period of time and would be paid for through increased utilities charges. Construction would be phased according to a priority system. The first priority was associated with homes in the five study areas in areas historically subject to flooding. A second priority was for other homes in the city that had previously experienced basement flooding. The third priority was the remaining homes in the five study areas while the lowest priority was the remaining homes in the city. Rapid response to the first to priority areas would provide a significant level of protection against basement backups with the installation of backflow prevention valves in the basement level plumbing. The disconnection program will be implemented neighborhood by neighborhood to minimize traffic and other local disruptions and to tie into the shallows drains to the stormwater system in one operation. Residents would not be forced into implementing the disconnection but the future sale of the home would be contingent on the disconnection being made. Financial incentives to implement the disconnection at the time of the neighborhood program include a reimbursement only if the disconnect is implemented when the local construction is implemented as well as increases in user fees for failure to implement the disconnection.

\subsection{Conclusions}

A study implemented following a major rainfall event that caused several hundred incidents of basement flooding through the backup of the sanitary sewer system indicated that up to $90 \%$ of wet weather infiltration into the system was due to flows from connected footing drains, a practice that is no longer permitted under the current city building codes. Investigation of potential alternatives to eliminate recurrence of the flooding indicated that disconnection of these footing drains would generally be the least cost alternative. However, a large percentage of homes, including many that had never experienced basement flooding, would need to be disconnected eliminating the prospects for success of a voluntary disconnect program. Implementation issues associated with a mandatory disconnect program led to a decision to implement footing drain disconnections city-wide. The advantages to such a program are considered to be: 
- this solution places first priority on the protection of homes that had been previously impacted by sanitary sewer backups during major rainfall events;

- it eliminates the costs for treatment of the rainwater that would otherwise enter the wastewater collection system;

- it will reduce or eliminate the need for future wastewater treatment plant expansion and/or regulatory fines for sanitary sewer discharges to the environment;

- this solution does not move the flooding problems further downstream in the sanitary sewer system or require construction of downstream relief sewers; and

- the solution is compatible with trends in regulations that will encourage disconnections of footing drains from sanitary sewer systems.

\section{References}

Dillard, C.W., G.E. Kurz and P.A. Stonecipher (1993) "Management of Sewer System Rehabilitation for the Overflow Abatement Program in Nashville, Tennessee," Proceedings Pipeline Infrastructure Conference, San Antonio TX, pp. 449-467. Duggan, E.W., H. Goldberg, I.M. Woodfall, D.J. Doherty (1998) "Planning and Implementation of Trenchless Technologies to Restore the St. James, Boston Interceptor," Civil Engineering Practice, Vol. 13, No. 2, pp. 77-86.

Jennings, J.C. (1995) "Trenchless Sewer Replacement Pleases Neighborhood Residents," Public Works, Vol. 126, No. 8, pp. 32-33.

Kurz, G.E. (1997) "Predicting I/I Reduction for Planning Sewer Rehabilitation," Proceedings ASCE Conference on Trenchless Pipeline Projects, Boston MA, pp. 103-110;

Mines, R.O. (1996) "Wastewater Collection Systems," Water Environment Research, Vol. 68, No. 4, pp. 421-423.

Paulson, R.J., S.F. Wylie, D.S. Anderson, F. Miles and R.T. Godfrey (1984) “Attacking Private Inflow/Infiltration Sources," Public Works, vol. 115, No. 2, pp. 54-59.

Rowlett, T. (1992) "When Sewer Rehab Doesn't Stop Basement Flooding," Proceedings ASCE Water Forum, Baltimore MD, pp. 648-653.

Sanitary Sewer Overflow Prevention Task Force (2001) "Sanitary Sewer Overflow Prevention Study," Report to Ann Arbor City Council.

Wade, M.G(2000) “Sealing Springfield," Civil Engineering, Vol. 70, No. 5, pp. 52-55. Yach, R. (1997) "Dade County Rates Pipe Bursting Performance," Public Works, Vol. 128 , No. 7, pp. $62-63$. 